\title{
Bioactive glass/polymer composite scaffolds mimicking bone tissue
}

\author{
Piergiorgio Gentile, ${ }^{1}$ Monica Mattioli-Belmonte, ${ }^{2}$ Valeria Chiono, ${ }^{1}$ Concetta Ferretti, ${ }^{2}$ \\ Francesco Baino, ${ }^{3}$ Chiara Tonda-Turo, ${ }^{1}$ Chiara Vitale-Brovarone, ${ }^{3}$ Iva Pashkuleva, ${ }^{4,5}$ \\ Rui L. Reis, ${ }^{4,5}$ Gianluca Ciardelli, ${ }^{1,6}$ \\ ${ }^{1}$ Department of Mechanical and Aerospace Engineering, Politecnico di Torino, Corso Duca degli Abruzzi 24, 10129 Turin, Italy \\ ${ }^{2}$ Department of Clinical and Molecular Sciences-Histology, Università Politecnica delle Marche, Via Tronto 10/A, 60020 \\ Ancona, Italy \\ ${ }^{3}$ Institute of Materials Engineering and Physics, Applied Science and Technology Department, Politecnico di Torino, \\ Corso Duca degli Abruzzi 24, 10129 Turin, Italy \\ ${ }^{4} 3 B^{\prime}$ s Research Group-Biomaterials, Biodegradables and Biomimetics, University of Minho Headquarters of the European \\ Institute of Excellence on Tissue Engineering and Regenerative Medicine, AvePark, 4806-909 Taipas, Guimaraes, Portugal \\ ${ }^{5}$ IBB-Institute for Biotechnology and Bioengineering, PT Government Associated Laboratory, Braga, Portugal \\ ${ }^{6}$ CNR-IPCF UOS Pisa Via Moruzzi, 1, 56124 Pisa, Italy
}

Received 26 April 2011; revised 16 January 2012; accepted 30 March 2012

Published online 21 May 2012 in Wiley Online Library (wileyonlinelibrary.com). DOI: 10.1002/jbm.a.34205

\begin{abstract}
The aim of this work was the preparation and characterization of scaffolds with mechanical and functional properties able to regenerate bone. Porous scaffolds made of chitosan/gelatin (POL) blends containing different amounts of a bioactive glass (CEL2), as inorganic material stimulating biomineralization, were fabricated by freeze-drying. Foams with different compositions (CEL2/POL 0/100; 40/60; 70/30 wt \%/wt) were prepared. Samples were crosslinked using genipin (GP) to improve mechanical strength and thermal stability. The scaffolds were characterized in terms of their stability in water, chemical structure, morphology, bioactivity, and mechanical behavior. Moreover, MG63 osteoblast-like cells and periostealderived stem cells were used to assess their biocompatibility. CEL2/POL samples showed interconnected pores having an average diameter ranging from $179 \pm 5 \mu \mathrm{m}$ for CEL2/POL 0/ 100 to $136 \pm 5 \mu \mathrm{m}$ for CEL2/POL 70/30. GP-crosslinking and the increase of CEL2 amount stabilized the composites to
\end{abstract}

water solution (shown by swelling tests). In addition, the SBF soaking experiment showed a good bioactivity of the scaffold with 30 and 70 wt \% CEL2. The compressive modulus increased by increasing CEL2 amount up to $2.1 \pm 0.1 \mathrm{MPa}$ for CEL2/POL $70 / 30$. Dynamical mechanical analysis has evidenced that composite scaffolds at low frequencies showed an increase of storage and loss modulus with increasing frequency; furthermore, a drop of $E^{\prime}$ and $E^{\prime \prime}$ at $1 \mathrm{~Hz}$ was observed, and for higher frequencies both moduli increased again. Cells displayed a good ability to interact with the different tested scaffolds which did not modify cell metabolic activity at the analyzed points. MTT test proved only a slight difference between the two cytotypes analyzed. ( 2012 Wiley Periodicals, Inc. J Biomed Mater Res Part A: 100A: 2654-2667, 2012

Key Words: bioactive glass, chitosan, composite, gelatin, periosteal precursor cells

How to cite this article: Gentile P, Mattioli-Belmonte M, Chiono V, Ferretti C, Baino F, Tonda-Turo C, Vitale-Brovarone C, Pashkuleva I, Reis RL, Ciardelli G. 2012. Bioactive glass/polymer composite scaffolds mimicking bone tissue. J Biomed Mater Res Part A 2012:100A:2654-2667.

\section{INTRODUCTION}

The development of regenerative bone graft substitutes and bone tissue engineering scaffolds is an important area in the field of biomaterials and orthopedics, in a busy scenario for academia, industry, and clinicians, especially since several commercial bone graft substitute products were successfully applied in the clinics. ${ }^{1}$ The strategy of designing scaffolds able to regenerate bone with good mechanical and functional properties is a promising alternative to the use of allografts, autografts, and metals. Scaffolds for bone repair should be based on biomaterials with adequate properties such as biocompatibility, osteoconduction, bioactivity, osteoinduction, and biodegradation. ${ }^{2}$ Bone regeneration usually employs three-dimensional (3D) porous materials. The 3D porous structure provides the necessary support for cells to proliferate and maintain their differential function, and its architecture defines the ultimate shape of new bone. $^{3}$ Moreover, scaffolds for bone regeneration should mimic bone morphology, structure, and function. Bone is composed of calcium phosphate (69-80 wt \%, mainly hydroxyapatite), collagen (17-20 wt \%), and other components (water, proteins, etc.). ${ }^{4}$ For this reason, composites based on apatite crystals and natural polymers have received increasing attention in bone tissue engineering

Correspondence to: G. Ciardelli; e-mail: gianluca.ciardelli@polito.it

Contract grant sponsor: Italian Ministry of University and Research for Piergiorgio Gentile's PhD Grant

Contract grant sponsor: FIRB project; contract grant number: RBAP10MLK7 
applications due to their ability to preserve the structural and biological phenotype of the damaged hard tissues in a biomimetic way. ${ }^{5}$ 3D sponge-like composite scaffolds based on bioactive glass and a genipin-crosslinked network of chitosan/gelatin were obtained by freeze-drying and investigated, having a similar composition to that of natural bone. Bioactive glasses are formed of different compositions of $\mathrm{SiO}_{2}$ with the addition of $\mathrm{Na}_{2} \mathrm{O}, \mathrm{CaO}$, and $\mathrm{P}_{2} \mathrm{O}_{5}$; they react with physiological fluids and form strong chemical bonds with the native tissue. ${ }^{6,7}$ Bioactive glasses have successfully served as skeletal substitutes and to fill bone defects in the oral cavity, largely because of their osteoconductive properties. ${ }^{8,9}$ To retain these materials in a local defect site, bioactive glasses have been incorporated into composites with synthetic polymers for improved delivery and degradation. ${ }^{10,11}$ While most osteoconductive biomaterials predominantly serve as a passive site for cellular adhesion, proliferation, and differentiation, recent reports have demonstrated that bioactive glasses may play a more active role in directing cellular behavior. ${ }^{12,13}$ Bioglass $^{\circledR} 45 S 5$ has exhibited the potential to support the growth of osteoblasts and their precursors in vitro and to favor osteoblast differentiation by stimulating the synthesis of phenotypic markers such as alkaline phosphatase, Type I collagen, and osteocalcin. ${ }^{13-15}$ Moreover, chitosan, a naturally derived polysaccharide, was used as organic component of the composite scaffold. It has gained much attention as a biomaterial in diverse tissue engineering applications due to its low cost, large-scale availability, anti-microbial activity, and biocompatibility. ${ }^{16}$ Chitosan films are highly brittle with a strain at break of $40-50 \%$ in the wet state, while chitosan scaffolds with various shapes, pore sizes, and pore orientation can be obtained using freezing at a controlled-rate followed by lyophilization. ${ }^{16}$ Furthermore, lysozyme-dependent chitosan degradation is influenced by the degree of deacetylation (DD), ${ }^{17}$ local $\mathrm{pH}^{18}$ and homogeneity of the source; lysozymal hydrolysis is high in acidic conditions $(\mathrm{pH}=4.5-5.5)^{19}$ and decreases with increasing DD. The mechanical or biological properties of chitosan can be significantly improved by blending with other polymers. ${ }^{20}$ Gelatin, a nonexpensive and commercially available biomaterial that has gained interest in biomedical engineering, mainly because of its biodegradability, has been blended with chitosan to improve the biological activity since (i) it contains Arg-Gly-Asp (RGD)-like sequences that promote cell adhesion and migration, and (ii) it may form a polyelectrolyte complex with chitosan. Gelatin-chitosan scaffold has been formed without or with cross-linkers such as glutaraldehyde ${ }^{21}$ or enzymes, ${ }^{22}$ and tested for the regeneration of various tissues including skin, ${ }^{23}$ cartilage, ${ }^{24}$ and bone.

The scaffolds were prepared by freeze-drying process that is a conventional technique for the fabrication of porous materials in which pore structure is controlled by the ice crystal growth. Optimal pore diameters for 3D porous structures for bone repair are in the 100-400 $\mu \mathrm{m}$ range. $^{25}$

In this work, physical, chemical, and mechanical properties and the bioactivity of composite porous scaffold were investigated. Moreover, to assess their biocompatibility and possible use for the regeneration of osteochondral tissues, the interaction with MG63 osteoblast-like cells and periosteal progenitor cells (PCs) was evaluated. The latter present a cell-surface marker profile similar to mesenchymal stem cells (MSCs) that are prominent candidate cells to repair complex skeletal tissue defects. ${ }^{26}$ MSCs, in fact, have a pronounced expansion capacity, undergo no allogeneic rejection after transplantation, and show a high plasticity. PCs also have the potential to differentiate into bone, cartilage, fat, and muscle ${ }^{27}$ and recent studies evaluating migration, homing, or engraftment potential of human PCs strengthened the hypothesis of periosteum as an interesting cell source for a bone tissue regenerative medicine. ${ }^{28}$

\section{EXPERIMENTAL SECTION}

\section{Materials}

Type A gelatin (CAS No. G2500-100G) from porcine skin was supplied from Sigma, Italy. Chitosan derived from crab shell with $76.5 \%$ deacetylation degree was purchased from Sigma, Milan, Italy. The degree of deacetylation was determined by FT-IR spectroscopy using the following formula: ${ }^{29}$

$$
\% \mathrm{DD}=100-\left[\left(\mathrm{A}_{1320} / \mathrm{A}_{1420}\right)-0.3822\right] / 0.03133
$$

where $A_{1320}$ is the absorbance at $1320 \mathrm{~cm}^{-1}$, and $A_{1420}$ is the absorbance at $1420 \mathrm{~cm}^{-1}$.

Bioactive glass (CEL2, particle size $<30 \mu \mathrm{m}$ ) was prepared according to a published procedure. ${ }^{30}$ Genipin (GP) was purchased from Challenge Bioproducts, Taiwan. All solvents used were of analytical grade and used without further purification.

\section{Methods}

Preparation of crosslinked CEL2/POL scaffolds. A 3\% (w/ v) $\mathrm{CH}-\mathrm{G}$ solution in $0.5 \mathrm{M}$ acetic acid (Sigma, Italy) was prepared under stirring for $12 \mathrm{~h}$ at $40^{\circ} \mathrm{C}$. $\mathrm{CH}$ and G were mixed at 1:2 weight ratio. CEL2 was added to the polymeric solution (POL) to obtain CEL2/POL composites with various weight ratios between the components: $0 / 100 ; 40 / 60 ; 70 /$ 30 (wt \%/wt.). The composites were coded as follows: CEL2/POL 0/100; 40/60; 70/30. For crosslinked samples, GP was added to CEL2/POL solutions at defined weight percentage (2.5 wt \%/wt with respect to the gelatin/chitosan amount). Each mixture was kept at $50^{\circ} \mathrm{C}$ under stirring until a gel started to form. The gel was spread on Petri dishes (different sizes according to the specific tests) and freezedried (Scanvac, CoolSafe) at $-20^{\circ} \mathrm{C}$ for $24 \mathrm{~h}$ to obtain porous polymeric matrices. After freeze-drying, samples were washed several times alternating $0.1 \mathrm{~N} \mathrm{NaOH}$ solution and demineralized water to remove GP residues and then samples were freeze-dried again.

Analysis of the porosity and the microstructure of scaffolds using micro-computed tomography. Scaffold architecture was analyzed using micro-computed tomography ( $\mu$-CT) with a desktop micro CT scanner (SkyScan 1072, Aartselaar, Belgium). No contrasting agent was added and the samples had a minimum size of $4 \times 4 \times 2 \mathrm{~mm}^{3}$. 
The scanner was set at a voltage of $40 \mathrm{kV}$ and a current of $248 \mathrm{~A}$, and the samples were scanned at $8.71 \mu \mathrm{m}$ pixel resolutions by approximately 350 slices covering the sample height of $2.5 \mathrm{~mm}$. For imaging, the sliced 2D tomographic raw images were reconstructed using CT Analyzer software, and the threshold levels of the grayscale images were equally adjusted for all the samples to allow the measurement of the volume of pores, providing the data for scaffold porosity. 3D modeling was also used to analyze the scaffold structure in a nondestructive manner, using imaging software.

\section{Swelling tests}

The extent of swelling was determined by a conventional gravimetric procedure as reported in literature. ${ }^{31}$ Weighed amounts of crosslinked CEL2/POL scaffolds (13 mm diameter and $5 \mathrm{~mm}$ height, as measured by means of a caliber) were kept in Phosphate Buffer Saline (PBS, Sigma, Italy) at $37^{\circ} \mathrm{C}(\mathrm{pH}=7.4)$. Swollen porous matrices were drawn at various time intervals $(6,12$, and $24 \mathrm{~h})$, dried superficially by gentle contact with a filter paper and weighed for the determination of wet weight as a function of the immersion time.

The swelling percentage was calculated as

$$
\% \mathrm{Sw}=\left[\left(\mathrm{W}_{\mathrm{s}}-\mathrm{W}_{\mathrm{i}}\right) / \mathrm{W}_{\mathrm{i}}\right] \times 100
$$

where $W_{\mathrm{i}}$ and $W_{\mathrm{s}}$ are the sample weights before and after swelling, respectively. Each test was repeated three times for each composition and results were expressed as average value \pm standard deviation.

\section{Bioactivity evaluation}

To study the bioactivity of samples, porous scaffolds (13 $\mathrm{mm}$ diameter and $5 \mathrm{~mm}$ height, as measured by means of a caliber) were soaked in $5 \mathrm{~mL}$ of SBF prepared according to the protocol described by Kokubo et al., ${ }^{32}$ at $37^{\circ} \mathrm{C}$ and $\mathrm{pH}$ 7.4 for various time intervals $(2,7$, and 14 days, refresh of solution once every 2 days). SBF has a composition similar to human blood plasma and has been extensively used for in vitro bioactivity test. At the end of each experiment, the specimens were removed from SBF and then abundantly rinsed with deionized water and freeze-dried for morphological analysis and compositional examination.

\section{Mechanical characterization}

The compressive strength of the scaffolds was measured using a mechanical testing machine (MTS, QTest/10). Test specimens were cylinder-shaped composite foams with 1.6 $\mathrm{cm}$ diameter and an average height of around 1-1.2 cm measured by means of a caliber. Five porous samples were evaluated for each composition. The samples were tested at room temperature. The cross-head speed was set at 0.01 $\mathrm{mm} \cdot \mathrm{s}^{-1}$ and the load were applied until the specimen was compressed to approximately $60 \%$ of its original length. The compressive stress-strain curves were thus obtained and the average compressive modulus with its standard deviation was calculated for each sample. Precisely, the modulus was determined as the slope of the initial linear portion of the stress-strain curve. ${ }^{33}$

Furthermore, dynamic mechanical analysis (DMA) was carried out on the prepared scaffolds to investigate their behavior under cyclic compressive load. The scaffolds were tested in a dry state; specifically, the samples underwent dynamic compressive solicitation (load condition: sinusoidally varying load of $110 \mathrm{mN}$ superimposed to a static load of $100 \mathrm{mN}$ ) at increasing frequencies varying from 0.1 to 40 $\mathrm{Hz}$ (DMA7 Perkin-Elmer analyzer). This frequency range is typical for load-bearing conditions in physiological situations. $^{34,35}$ Storage $\left(E^{\prime}\right)$ and loss $\left(E^{\prime \prime}\right)$ modulus, that are the real and imaginary component, respectively, of the complex modulus $E=E^{\prime}+i E^{\prime \prime}(i=\sqrt{-1}$ is the imaginary unit), were recorded against frequency. ${ }^{36}$

\section{In vitro culture}

Human osteoblast-like cell line MG63 and human periostealderived precursor cells (PCs) were used for in vitro tests

MG-63 human osteoblast-like cells (ATCC, Rockville, MD) were grown in a controlled atmosphere $\left(5 \% \mathrm{CO}_{2} ; \mathrm{T}=37^{\circ} \mathrm{C}\right)$ in Dulbecco's Modified Eagle's Medium (DMEM, SigmaAldrich, Milan, Italy) supplemented with $10 \%$ fetal bovine serum (FBS), 1\% nonessential amino acids $2.0 \mathrm{mM}$ L-glutamine, and 1\% penicillin-streptomycin (all from GIBCO, Invitrogen, Milan, Italy). After thawing, cells were routinely split 1:10 every 3-4 days and used between the third and fourth passages

PCs cells were isolated from periosteal tissue of subjects undergoing surgery for orthopedic trauma, after the obtainment of their informed consent. Tissue was aseptically dissected, washed three times in PBS, cut into small pieces $(2-3 \times 2-3 \mathrm{~mm})$, and placed into culture dish in Dulbecco's Modified Eagle Medium: Nutrient Mixture F-12 (DMEM/F12 GIBCO), supplemented with $10 \%$ FBS and $1 \%$ penicillinstreptomycin $(100 \mathrm{U} / \mathrm{mL})$. The cells were then allowed to adhere in standard cell culture conditions in a controlled atmosphere $\left(5 \% \mathrm{CO}_{2} ; \mathrm{T}=37^{\circ} \mathrm{C}\right)$. The medium was changed twice a week and cells were used between third and sixth passage of subculture. To assess PCs mesenchymal stem cells phenotype cells were characterized by FACSCalibur flow cytometry system (Becton Dickinson, CA,USA), using antibodies against the following surface antigens: HLA-DR, CD34, CD105, CD14, CD19, and CD45 (Diaclone, Besancon, France); CD73 and CD90 (StemCell Technologies, Inc. Vancouver, BC, and Canada). ${ }^{37}$

\section{Cell seeding}

Before seeding the freeze-dried CEL2/POL2 scaffolds were disinfected in 70\% ethyl alcohol solution (ETOH; SigmaAldrich, Milan, Italy) for $2 \mathrm{~h}$, washed two times in sterile PBS (GIBCO) for $30 \mathrm{~min}$ and sterilized under UV $15 \mathrm{~min}$ for each side. To improve cell adhesion, scaffolds were then conditioned overnight in $10 \%$ serum added DMEM or $\mathrm{DMEM} / \mathrm{F} 12$ at $5 \% \mathrm{CO}_{2}, 37^{\circ} \mathrm{C}$. The medium was then discarded and scaffolds considered ready for seeding. Cells were detached using $0.25 \%$ trypsin in $1 \mathrm{~m} M$ ethylenediaminetetraacetic acid (EDTA, Sigma-Aldrich, Milan; Italy) and 
seeded at a density of $1 \times 10^{4}$ cell $/ \mathrm{cm}^{3}$ by applying $50 \mu \mathrm{L}$ of cell suspension on the samples placed in at $37^{\circ} \mathrm{C}$ for 30 min in a humified chamber, to avoid the slip down of cells. Then $1.5 \mathrm{~mL}$ of the appropriate culture media was added to cover the samples placed in Corning ${ }^{\circledR}$ ultra-low attachment multiwell plates. Cells were cultured for 14 and 21 days.

\section{Histology}

Cultured scaffolds were fixed in $4 \%$ paraformaldehyde in $0.1 \mathrm{M}$ phosphate buffer, $\mathrm{pH} 7.4$, at $4^{\circ} \mathrm{C}$ for $20 \mathrm{~min}$ and washed three times with PBS and cut. Sections were taken from the peripheral and the central part of the scaffold, stained with $1 \mathrm{mg} / \mathrm{mL} \mathrm{4}$ ', 6-diamidino-2-phenylindole (DAPI D9542-Sigma-Aldrich) to stain cell nuclei, for $5 \mathrm{~min}$ at room temperature. Fluorescence images were photographed using a Zeiss AxioCam MRcs fluorescence microscope (Carl Zeiss Optical Inc., Germany) equipped with a Nikon DXM1200F Ultra High-Quality Digital Camera (NITAL S.p.A., Turin, Italy).

\section{MTT (3-dimethylthiazol-2,5-diphenyltetrazolium bromide) colorimetric assay}

After incubation (14 and 21 days), the medium was removed; $200 \mu \mathrm{L}$ of MTT (Sigma, Milan, Italy) solution (5 $\mathrm{mg} / \mathrm{mL}$ in DMEM without phenol red) and $1.8 \mathrm{~mL}$ of DMEM were added to the cell monolayer; the multi-well plates were incubated at $37^{\circ} \mathrm{C}$ for further $4 \mathrm{~h}$. After discarding the supernatants, the dark blue Formosan crystals were dissolved by adding $2 \mathrm{~mL}$ of solvent $(10 \% \mathrm{HCl} 1 \mathrm{~N}$ in isopropanol, Sigma, Milan, Italy) and quantified spectrophotometrically (Secomam, Anthelie light, version 3.8, Contardi, Italy) at 570 and $690 \mathrm{~nm}$. In the control cultures, the cells were placed directly into adherent polystyrene culture plates at the same culture density as placed onto the samples. The mean and the standard deviations were obtained from three different experiments of the same specimen.

\section{Morphological and compositional characterization (SEM-EDS)}

Morphological analysis (SEM; Philips 525M) and compositional analysis (EDS, Philips EDS 9100) were performed on surfaces and fractured sections (in liquid nitrogen) of all composite specimens. The samples were sputter coated with silver prior to examination.

Samples from cell culture tests were fixed in $2 \%$ glutaraldehyde (Sigma-Aldrich) in $0.1 \mathrm{M}$ cacodylate buffer (pH 7.4, Sigma-Aldrich), post-fixed in 1\% osmium tetroxide (Sigma, Milan, Italy), dehydrated in increasing ethanol (SigmaAldrich) concentrations, CPD-dried, mounted on aluminum stubs, gold-sputtered by the Edwards Sputter Coater B150S equipment, and observed with a Philips XL 20 SEM (FEI Italia SRL, Milan, Italy) microscope.

\section{Statistical Methods}

All quantitative data were presented as mean \pm standard deviation, unless otherwise noted. Statistical analysis was carried out using single-factor analysis of variance (ANOVA). A value of $p<0.05$ was considered statistically significant.

\section{RESULTS AND DISCUSSION}

\section{Porosity and morphological analysis}

The physical characteristics of a scaffold can be described by the average pore size, pore size distribution, pore volume, pore interconnectivity, and pore shape. Porosity (\% vol) is defined as the percentage of void space in a solid; ${ }^{38}$ it is a morphological property independent on the material. Pores are necessary for bone tissue formation because they allow migration and proliferation of osteoblasts and mesenchymal stem cells, as well as the proper vascularization of the implant. ${ }^{39}$ In addition, a porous surface improves the mechanical interlocking between the implant biomaterial and the surrounding natural bone, providing greater mechanical stability at this critical interface. ${ }^{40}$ Optimal pore diameters for 3D porous structures for bone repair are in the $100-400 \mu \mathrm{m}$ range, ${ }^{25}$ suitable for human osteoblast cell penetration, and a minimum pore size is required for tissue ingrowth, ${ }^{41}$ interconnectivity for access to nutrients and transport of waste products and pore shape, and roughness for better cell spreading. ${ }^{42}$

The porosity analysis within the scaffolds was determined by $\mu-C T$ analysis. Pore distribution and 3D-reconstruction of scaffolds are shown in Figure 1 and Table I. The porosity was found to vary from 67.1 to $84.8 \%$ depending on the percentage addition of CEL2. In particular, the total porosity decreased with increasing CEL2 amount because the bioactive glass particles were deposited onto the $\mathrm{G} / \mathrm{CH}$ walls and they filled part of void space of $\mathrm{G} / \mathrm{CH}$ matrix, as confirmed subsequently by SEM examination [Fig. 2(b,c)]. A 3D representation of the scaffolds is shown in Figure 1 and was used to calculate the pore size distribution. All results demonstrated that the scaffolds exhibited a porous distribution with both macropores (size between 75 and $300 \mu \mathrm{m}$ ) and micropores (size 1-75 $\mu \mathrm{m}$ ), which presence is crucial for protein and cell adhesion. Detailed analysis indicated that $80 \%$ of pores within the resultant scaffolds had a pore size in the range of $75-300 \mu \mathrm{m}$. The mean pore size was found to vary from $179.3 \mu \mathrm{m}$ for CEL2/POL 0/100 scaffolds to $136.2 \mu \mathrm{m}$ for CEL2/POL 70/30 composites. Moreover, in all composite porous matrices, a high interconnected network of pores (about 95.6-97.5\% by $\mu$-CT analysis) was observed. Pore size may be controlled by the temperature set in the freeze-drying process: pore diameters increase with increasing temperature due to a higher ice crystal growth rate. ${ }^{43}$ The pores within the scaffold arise from the ice crystals that form during freezing of the $\mathrm{G} / \mathrm{CH}$ solution. This process forces the polymer to form aggregates in the interstitial spaces and creates an interconnected network of polymer fibrils. A previous study has reported that the pore size of a gelatin scaffold can be adjusted by altering the polymeric concentration, the freezing rate and the $\mathrm{pH}$ value since these factors are known to affect both the nucleation and the growth rate of the ice crystals. ${ }^{44} \mathrm{~A}$ higher gelatin concentration and higher freezing rate of the dispersion produced a lower porosity and smaller pores. Higher porosity and larger pore sizes scaffolds could be obtained by a lower polymeric concentration and low freezing rate. 

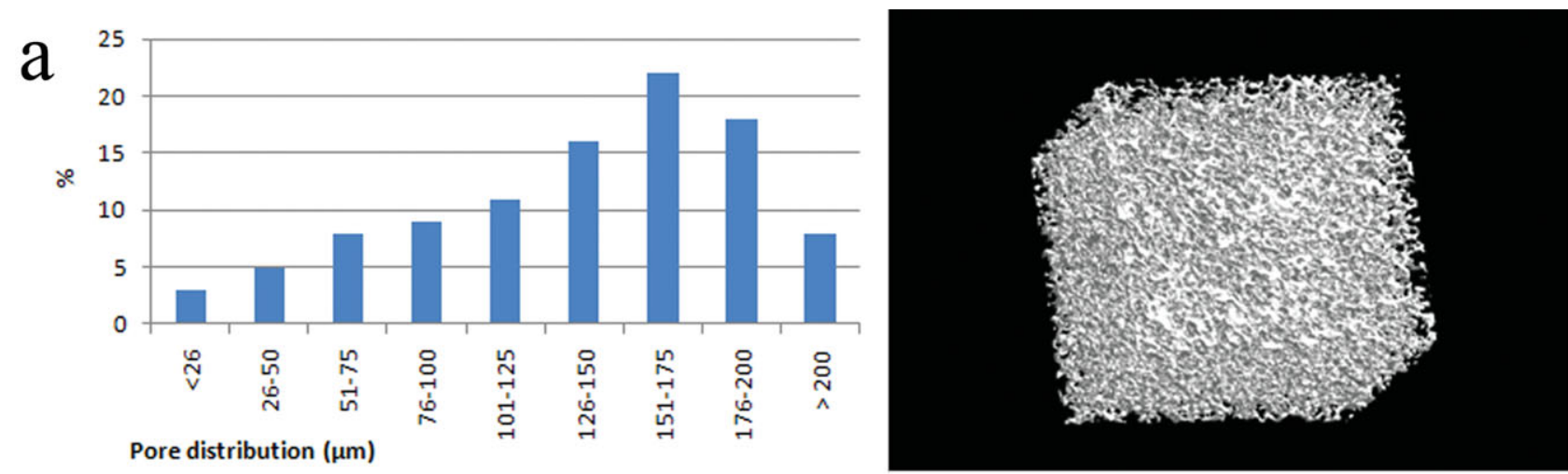

b
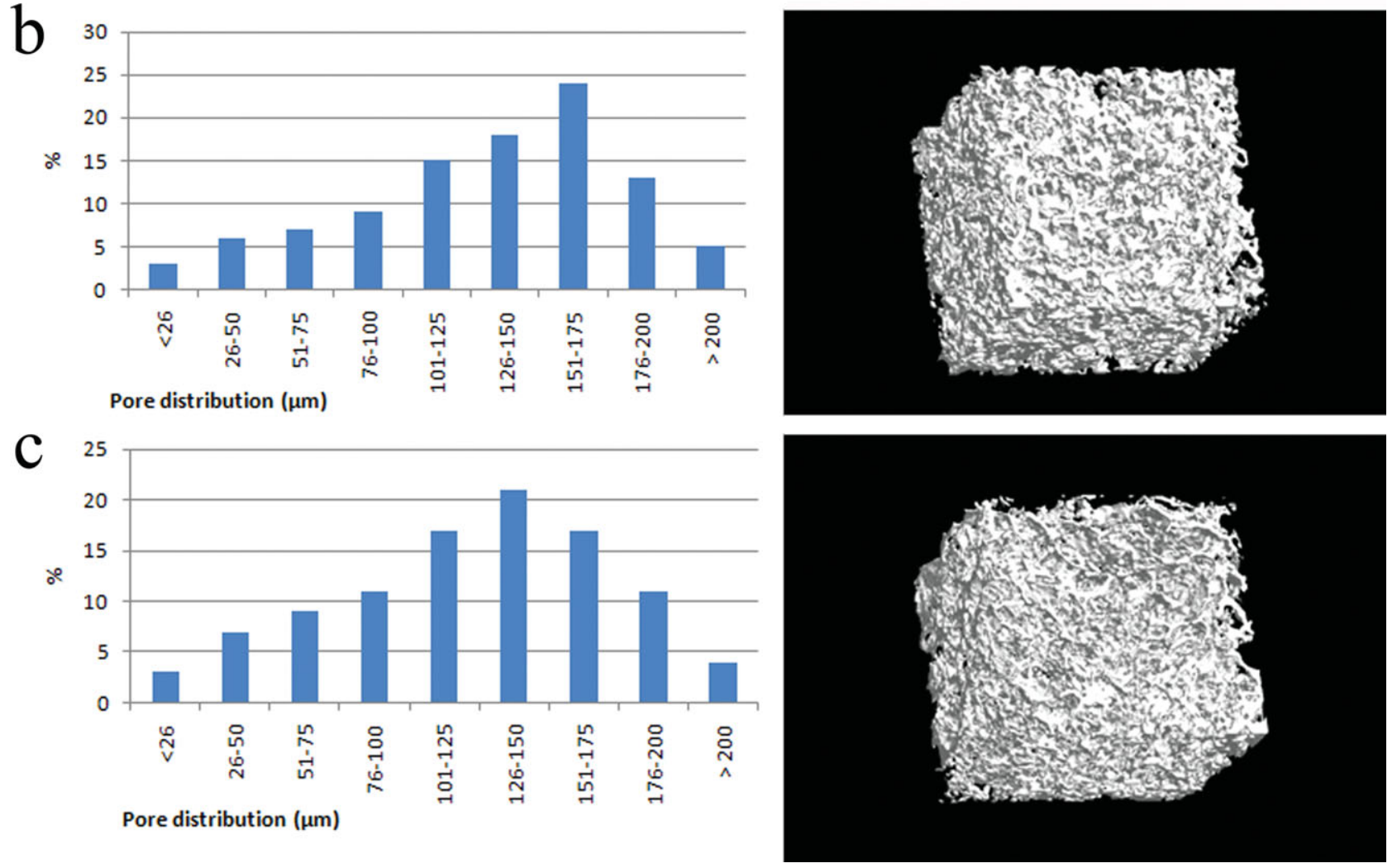

FIGURE 1. Pore distribution and 3D-reconstruction of (a) CEL2/POL 0/100 (b) CEL2/POL 40/60 (c) CEL2/POL 70/30 scaffolds as obtained by $\mu$-CT. [Color figure can be viewed in the online issue, which is available at wileyonlinelibrary.com.]

It should be noted that the $\mu$-CT pore size analysis in this study was performed on dry scaffolds. Generally, the polymeric scaffold shrinks in the drying process. The scaffold will expand when wetted in aqueous solution as reported in the paragraph relative to swelling tests; so the pore size in the wet condition will be larger than that reported above.

SEM analysis was performed on selective portions of the composite scaffolds to evaluate the effect of composition on sample morphology. Figure 2 reports SEM images of the fractured sections with the corresponding EDS spectra of CEL2/POL scaffolds. Porous scaffolds showed a typical foam-like morphology with interconnected pores with a wide distribution of pore sizes and wall thickness. As it can be observed in Figure 2, pore walls increased their thickness with increasing CEL2 amount, which gave the foams a more compact structure. For scaffolds containing 40 wt \% of bioactive glass, CEL2 clusters of several microns $(60-80 \mu \mathrm{m})$ were observed, but in composites containing 70 wt \% CEL2, the particles appeared more uniformly distributed. EDS spectra of G/CH scaffolds [Fig. 2(a)] showed the characteristic elements of gelatin and chitosan: carbon

TABLE I. Pore Data of CEL2/POL Scaffolds Obtained by $\mu$-CT

\begin{tabular}{lccc}
\hline $\begin{array}{c}\text { CEL2/POL } \\
\text { sample }\end{array}$ & $\begin{array}{c}\text { Porosity } \\
(\%)\end{array}$ & $\begin{array}{c}\text { Pore } \\
\text { interconnectivity }(\%)\end{array}$ & $\begin{array}{c}\text { Mean pore } \\
\text { size }(\mu \mathrm{m})\end{array}$ \\
\hline $0 / 100$ & 84.8 & 97.5 & 179.3 \\
$40 / 60$ & 72.5 & 96.0 & 160.6 \\
$70 / 30$ & 67.1 & 95.6 & 136.2 \\
\hline
\end{tabular}




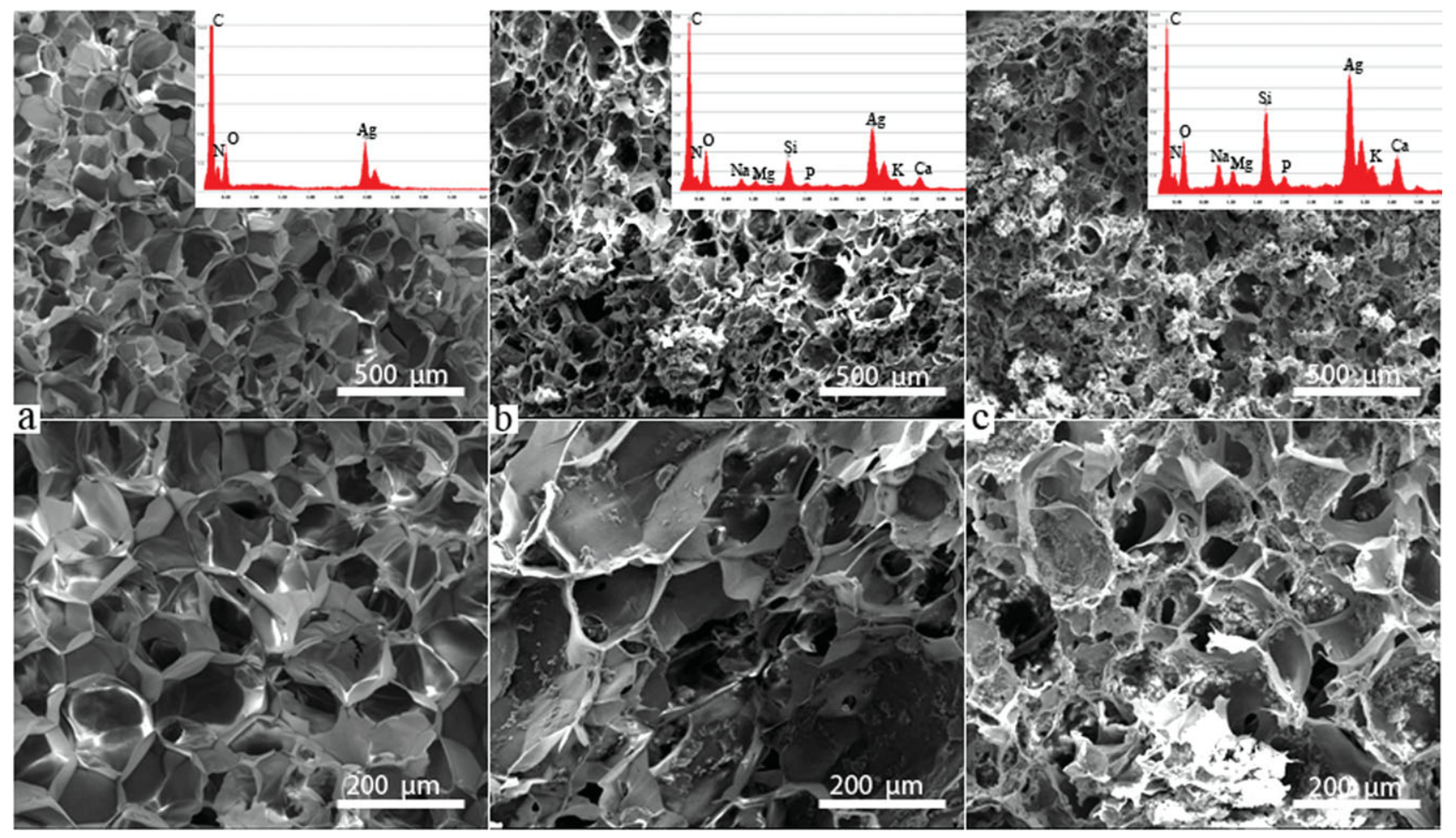

FIGURE 2. SEM micrographs and EDS spectra of CEL2/POL scaffolds: fractured section of (a) CEL2/POL 0/100, (b) CEL2/POL 40/60, (c) CEL2/POL 70/30. [Color figure can be viewed in the online issue, which is available at wileyonlinelibrary.com.]

$(\mathrm{C})$, nitrogen $(\mathrm{N})$, and oxygen (O) while EDS spectra of the composites showed also the characteristic elements of CEL2: silicon $(\mathrm{Si})$, potassium $(\mathrm{K})$, sodium $(\mathrm{Na})$, magnesium $(\mathrm{Mg})$, calcium (Ca), and phosphorus (P) [Fig. 2(b,c)].

\section{Swelling tests}

One of the main factors to contribute to biocompatible nature of biomaterials is the water content which imparts several unique physiochemical properties to the material. A polymer matrix imbibing an adequate amount of water shows similar properties to living tissue-like membranes: physiological stability, low interfacial tension, permeability to biomolecules, etc. ${ }^{45}$ Moreover, swelling increases also the pore size and total porosity, thus maximizing the internal surface area of the scaffolds. Scaffolds showing higher degree of swelling will have a larger surface area/volume ratio thus allowing the porous matrices to have the maximum probability of cell infusion into the 3D scaffold as well as maximum cell growth by attachment to the scaffold surfaces. The increase in swelling also allows the scaffold to avail nutrients from culture media more effectively. However, while the swelling would promote cell adhesion, it could lower its mechanical properties. Thus for CEL2/POL composites, the influence of chemical composition of the composites on their water intake has been investigated. Figure 3 reports the swelling degree as a function of time for composite porous matrices with different compositions. All composites showed a similar swelling behavior as a function of time: swelling degree slightly increased as a function of time from 6 to $24 \mathrm{~h}$. CEL2/POL 0/100 scaffolds displayed the maximum swelling degree at every time interval. At $6 \mathrm{~h}$, the swelling degree was about $884 \pm 47 \%$, while at 12 and $24 \mathrm{~h}$ the swelling ratio was $973 \pm 13 \%$ and $1049 \pm 40 \%$, respectively. For CEL2/POL 40/60 samples, at $6 \mathrm{~h}$ the swelling degree was about $568 \pm 29 \%$. At 12 and $24 \mathrm{~h}$, the swelling degree increased not significantly. Moreover, for CEL2/POL 70/30 composites, at $6 \mathrm{~h}$ swelling ratio was about $259 \pm 50 \%$, while at 12 and $24 \mathrm{~h}$, the swelling degree slightly increased.

At each time, swelling degree was found to decrease with increasing CEL2 amount. The results were not surprising and were attributed to the lower hydrophilicity of the inorganic phase as compared to the polymeric matrix: the increase in the inorganic fraction of the composite resulted in a decreased water sorption. In addition, the increasing polymer-bioactive glass interaction with increasing concentration of CEL2 resulted in a slower relaxation of polymer chains, which also decreased the swelling ratio.

\section{Bioactivity evaluation}

An essential requirement for an artificial material showing bioactivity is the formation of a biologically active bone-like apatite on its surface when in contact with the physiological environment. This property can be evaluated in vitro by incubation in SBF. There is an oscillating phenomenon of precipitation and dissolution processes in vitro, which is due to metastable SBF. It was reported that the precipitation and dissolution processes of bone like apatite take place during the immersion of bioactive materials in SBF. Hench reported that there is a good correlation of in vitro 


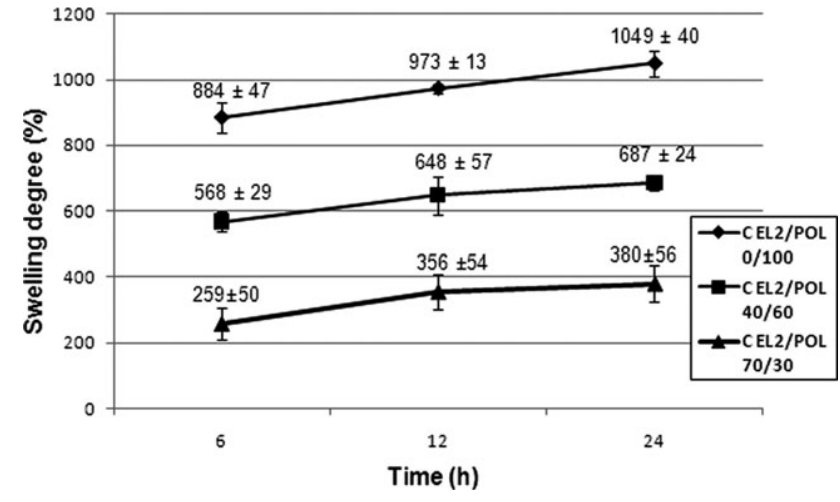

FIGURE 3. Swelling behavior of scaffolds as a function of time. Data are averaged on three measurements. Bars indicate standard deviation $(n=3)$.

bone-like apatite formation from SBF and in vivo bone-like apatite (calcium phosphate) formation needed to secure bone bonding. ${ }^{46}$ CEL2/POL composite scaffolds were investigated after immersion in SBF by SEM-EDS to check the formation of an apatite layer onto the composite surface. The interaction between the surface of the composites and SBF solution may be responsible for the apatite nucleation. Various bioactive ceramics such as TCP and Bioglass ${ }^{\circledR}$ have been developed to be used clinically in bone repair. ${ }^{47}$ These have been found to bond with bone through a layer of bone-like apatite formed on the surface of the ceramics when implanted into the body. This apatite has been characterized as carbonate-containing HA and was not observed at the interface between non-bioactive (or bio-inert) materials and bone. ${ }^{48}$

Figure 4 reports SEM images with the corresponding EDS spectra of the fractured section of CEL2/POL scaffolds after soaking in SBF for 2, 7, and 14 days, respectively. CEL2/POL 0/100 scaffolds did not induce the precipitation of calcium phosphate crystals at any test time as shown in Figure $4(\mathrm{a}, \mathrm{d}, \mathrm{g})$. As suggested by Cai and Kong. ${ }^{49,50} \mathrm{CH}$ and G are characterized by the lack of bioactivity, which severely limits their biomedical applications; thus this feature needs to be provided by the addition of biologically active materials. For composite scaffolds, after 2 days of incubation in

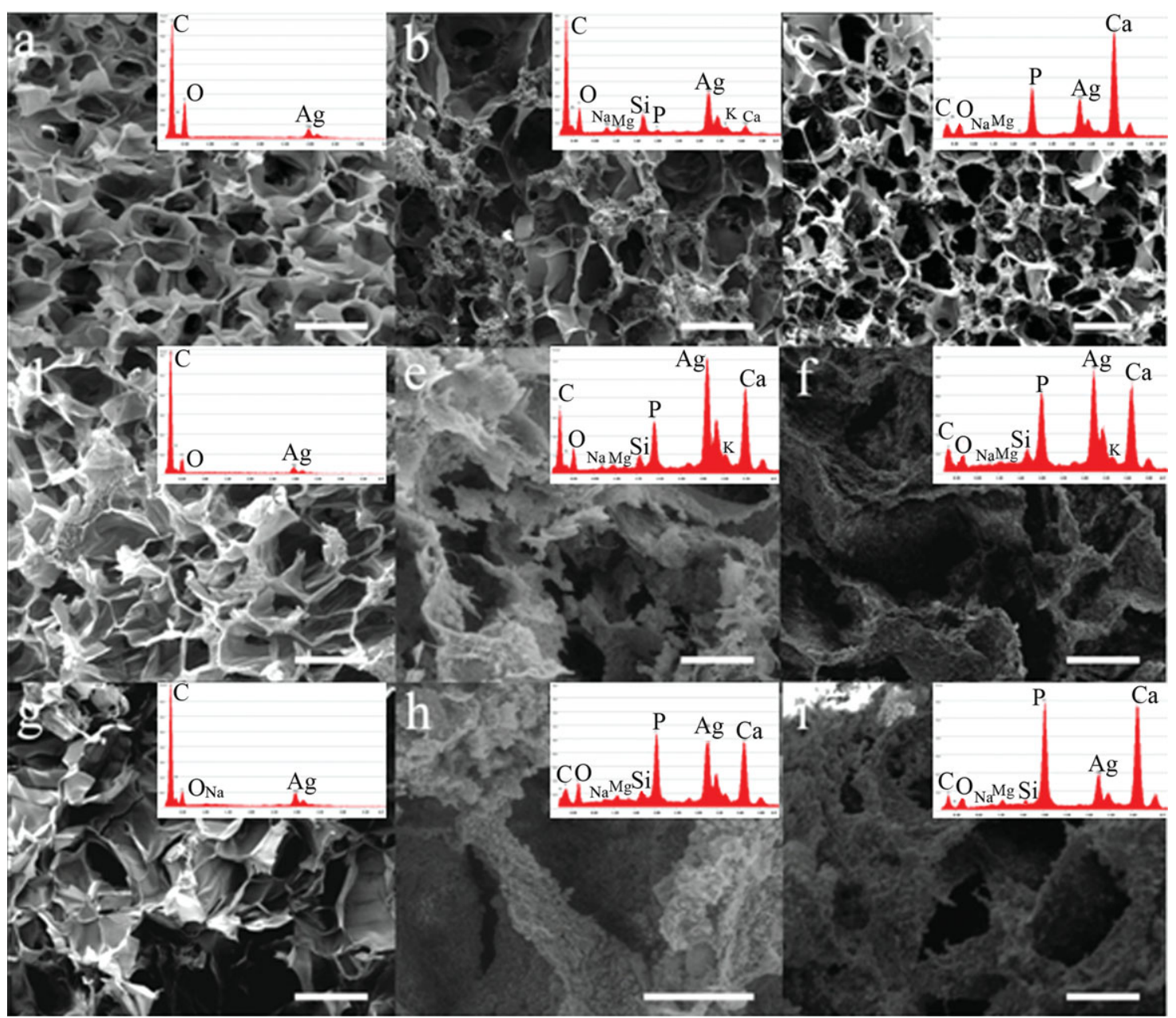

FIGURE 4. SEM micrographs and EDS spectra of CEL2/POL scaffolds after immersion in SBF for different intervals: after 2 days (a) CEL2/POL 0/ 100, (b) CEL2/POL 40/60, (c) CEL2/POL 70/30, after 7 days (d) CEL2/POL 0/100, (e) CEL2/POL 40/60, (f) CEL2/POL 70/30, and after 14 days (g) CEL2/ POL 0/100, (h) CEL2/POL 40/60, (i) CEL2/POL 70/30 (bar $100 \mu \mathrm{m}$ ). [Color figure can be viewed in the online issue, which is available at wileyonlinelibrary.com.] 

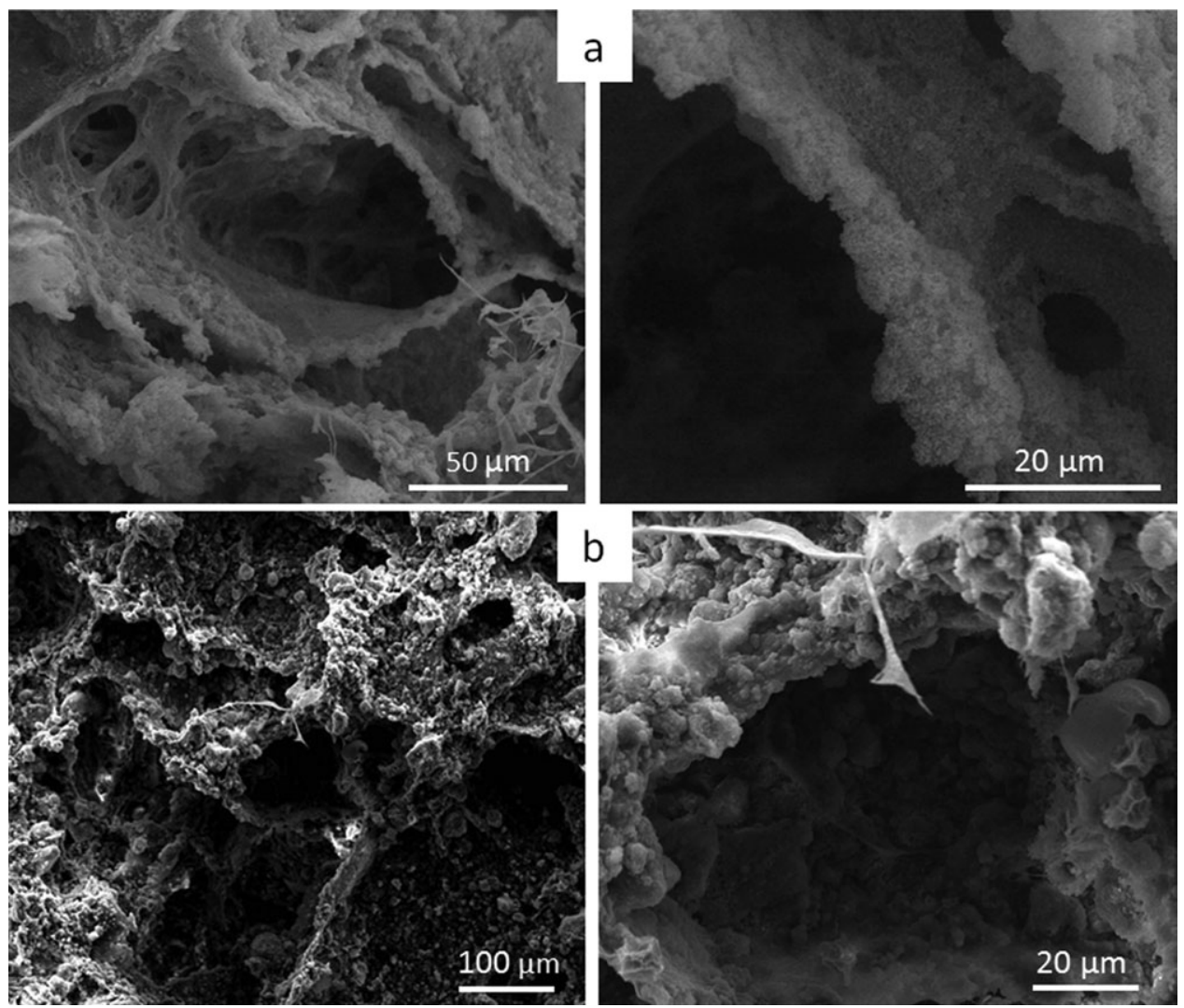

FIGURE 5. SEM micrograph magnifications of CEL2/POL scaffolds after immersion in SBF for 14 days: (a) CEL2/POL 40/60 and (b) CEL2/POL 70/30.

SBF, small amount of calcium phosphate crystals were observed as shown in Figure 4(b,c) (SEM image and EDS spectra). After 7 days of incubation, substantial amount of apatite microparticles with a diameter up to 2-4 $\mu \mathrm{m}$ were formed on the surface of the pore walls of the composite scaffolds [Fig. 4(e,f)]. After 14 days of incubation, the whole pores of CEL2/POL 40/60 and 70/30 composites were entirely covered by a layer of apatite [Fig. 4(h,i)]. Furthermore, the EDS spectra displayed the presence of small amounts of $\mathrm{Mg}, \mathrm{Si}, \mathrm{Na}$, and $\mathrm{K}$ ions incorporated in the mineral phases, due to the remaining CEL2. In conclusion, an increasing incubation time of the composite scaffolds in SBF (from 2 to 14 days) led to the formation of a higher amount of apatite. However, the interconnected macroporous structure of the scaffolds was maintained, which is important for cell migration and mass transport when the scaffolds is implanted in vivo. Moreover, after 14 days of immersion in SBF, EDS spectra recorded from the samples covered with the inorganic aggregates deposited on CEL2/POL scaffolds after SBF tests [Fig. 4(h,i)] allowed the calculation of $\mathrm{Ca} / \mathrm{P}$ molar ratio which resulted in 1.58 and 1.61 for CEL2/POL $40 / 60$ and 70/30, respectively. These values are very close to the stoichiometric Ca:P value of hydroxyapatite (1.67). ${ }^{51}$ Figure 5 shows the magnification of SEM micrographs relative to CEL2/POL 40/60 and 70/30 composites after 14 days of SBF immersion. The results indicate that the increasing addition of CEL2 enhances the bioactivity of composite scaffolds containing chitosan/gelatin as the organic phase. The mechanism of apatite formation in SBF was described by several researchers. ${ }^{52,53}$ It was reported that the formation of apatite on artificial materials is induced by functional groups which could reveal negative charge and further induce apatite deposition via the formation of amorphous calcium phosphate. In this research, the major reason for the enhancement of apatite formation on the composite scaffolds might be the bioactive glass particles acting as

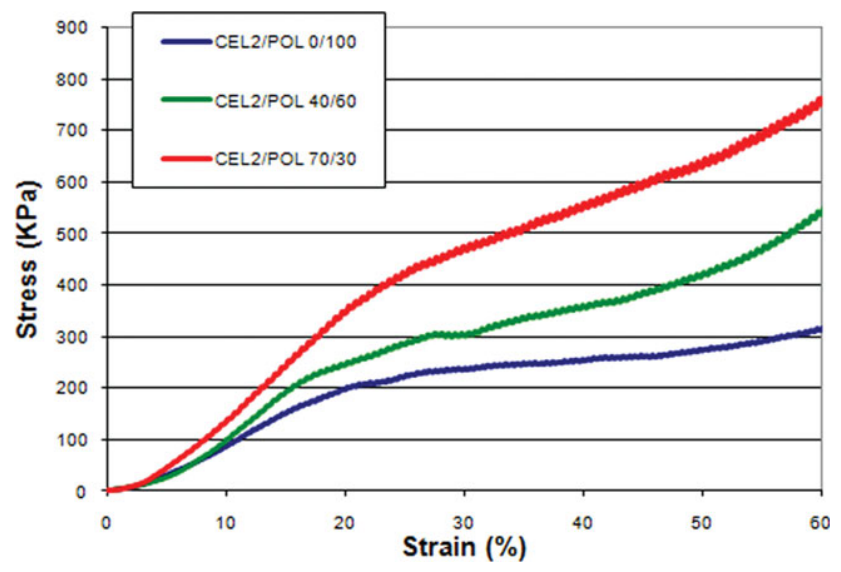

FIGURE 6. Stress-strain curves of the porous composite scaffolds compressed at a strain of $(0-60 \%)$. The cross-head speed was 0.01 $\mathrm{mm} \cdot \mathrm{s}^{-1}$. [Color figure can be viewed in the online issue, which is available at wileyonlinelibrary.com.] 
TABLE II. Elastic Modulus, Collapse Strength and Strain, and Collapse Modulus Calculated from the Corresponding StressStrain Curves

\begin{tabular}{lllll}
\hline CEL2/POL sample & $E^{*}(\mathrm{kPa})$ & $\sigma^{*}(\mathrm{kPa})$ & $\varepsilon^{*}(\%)$ & $\Delta \sigma / \Delta \varepsilon(\mathrm{kPa})$ \\
\hline $0 / 100$ & $1227.2 \pm 116.4$ & $203.5 \pm 21.8$ & $21.7 \pm 3.0$ & $203.7 \pm 41.2$ \\
$40 / 60$ & $1403.0 \pm 111.2$ & $214.1 \pm 6.4$ & $19.9 \pm 2.1$ & $350.1 \pm 38.2$ \\
$70 / 30$ & $2120.6 \pm 106.9$ & $374.0 \pm 7.1$ & $17.5 \pm 2.1$ & $737.2 \pm 38.6$ \\
\hline
\end{tabular}

nucleation initiation sites. In fact, CEL2 is a highly bioactive glass and the ability of CEL2 to induce the precipitation of HA (both as a macroporous scaffolds and as a filler in gelatin films) has been previously documented. ${ }^{54,55}$ An increasing amount of CEL2 in the composite scaffolds was associated with the presence of a higher density of nucleation sites for HA, and as a result a higher amount of apatite could be deposited at each time. Once the apatite nuclei have been formed, they can grow spontaneously by consuming the calcium and phosphate ions present in the surrounding fluid.

\section{Mechanical characterization}

One of the major critical point in developing load-bearing scaffolds for bone tissue engineering is the conflicting requirement of scaffolds with high porosity and mechanical strength. A highly porous structure is preferred in favor of cell growth and proliferation, but it is generally achieved at the expense of mechanical strength. In the scientific literature, compressive strength of substrates has often been found to decrease with increasing pore size. ${ }^{56}$ The mechanical properties of the porous composite scaffolds in terms of compressive strength were tested using a mechanical testing machine. The force was analyzed from stress-strain data obtained under a compressive load at a constant speed.

Figure 6 shows the stress-strain curves obtained for the porous composite scaffolds by the excessive compression test at strain of $0-60 \%$. During the test, the composites did not show a final fracture; rather, they underwent densification. The curves were classified in three distinct regions: linear elastic, collapse plateau, and densification regimes as reported in. ${ }^{57}$ The values of elastic modulus $\left(E^{*}\right)$, collapse strength, and strain ( $\sigma^{*}$ and $\varepsilon^{*}$, respectively), and collapse modulus $(\Delta \sigma / \Delta \varepsilon)$ were calculated from the curves are listed in Table II. A significant increase of compression Young's modulus was obtained by adding inorganic phase into the polymeric matrix, due to the superior compression behavior of CEL2 as compared to POL phase. As shown in Figure 6 and in Table II, the collapse strength and collapse strain were characterized by a different trend as a function of the CEL2 amount. In particular, the increase of the inorganic phase caused a progressive slight decrease in the deformability of the composite scaffold and an increase of the collapse strength and collapse modulus.

It is generally accepted that the scaffolding material for bone tissue engineering should have mechanical strength as close as possible to the strength of the bone to be repaired or substituted. In this study, a compressive modulus of 2.1 MPa was obtained for CEL2/POL 70/30 scaffold by adjusting processing conditions to achieve a highly densified porous structure. The obtained scaffolds, containing $70 \mathrm{wt}$ \% CEL2, had a compression Young's modulus comparable to the modulus of alveolar bone. ${ }^{58}$ Moreover, the composite matrices are expected to be suitable candidates for the articular cartilage/subchondral bone regeneration. As described above, a graded biomimetic osteochondral composite scaffold is necessary. Different methods were reported in literature to prepare bi-layered scaffolds, ${ }^{59-61}$ generally based on two consecutive different procedures (e.g. sintering and freeze-drying). In our case, graded scaffolds could be easily obtained by casting the mixture solutions before gelling: the lower water solubility and higher density of CEL2 as compared to the polymeric phase caused the progressive precipitation of CEL2 at the bottom of Petri dishes during solvent evaporation.

Both storage and loss modulus ( $E^{\prime}$ and $\left.E^{\prime \prime}\right)$ were measured in the frequency range $0.1-40 \mathrm{~Hz}$, which are typical frequencies found in physiological situations in load-bearing applications. ${ }^{62}$ The storage modulus $\left(E^{\prime}\right)$ is about one order of magnitude higher than the loss modulus $\left(E^{\prime \prime}\right)$ indicating an elastic nature of the scaffolds. The storage and loss modulus behavior as a function of the frequency of the loading cycle is reported in Figure $7(\mathrm{a}, \mathrm{b})$. The trend of both moduli is quite similar in each single scaffolds batch (CEL2/POL 0/ 100, CEL2/POL 40/60, or CEL2/POL 70/30), whereas the behavior differs in the case of different series (wholly polymeric or composite samples). As regards the wholly polymeric scaffolds, storage and loss modulus remained roughly constant at low (below $1 \mathrm{~Hz}$ ) and mid (1-10 Hz) frequencies, and showed an increase for higher frequencies. On the contrary, composite scaffolds (CEL2/POL 40/60 and CEL2/POL 70/30) are characterized by a more complex behavior, and the corresponding curves plotted in Figure $7(\mathrm{a}, \mathrm{b})$ can be divided into three distinct regions. At low frequencies (below $1 \mathrm{~Hz}$ ), both storage and loss modulus of porous composites increased with increasing frequency; afterward, there was a drop of $E^{\prime}$ and $E^{\prime \prime}$ around $1 \mathrm{~Hz}$, and for higher frequencies both moduli increased again. there is an increase in $E^{\prime \prime}$ for high frequencies, which suggests that the material exhibits some dissipation capability for high frequencies. Moreover, it is worth to underline that the storage modulus is about one order of magnitude higher than the loss modulus, which indicates the predominantly elastic nature of the prepared composite scaffolds in dry state. Although the Young's modulus, which was calculated from the slope of the initial part of the stress-strain curve, can be considered conceptually similar to the storage modulus, they could not be directly compared as the latter one is dependent on frequency. However, according to Malafaya et al., ${ }^{63}$ we considered $E^{\prime}$ and $E^{\prime \prime}$ acquired at a frequency of 
(a)

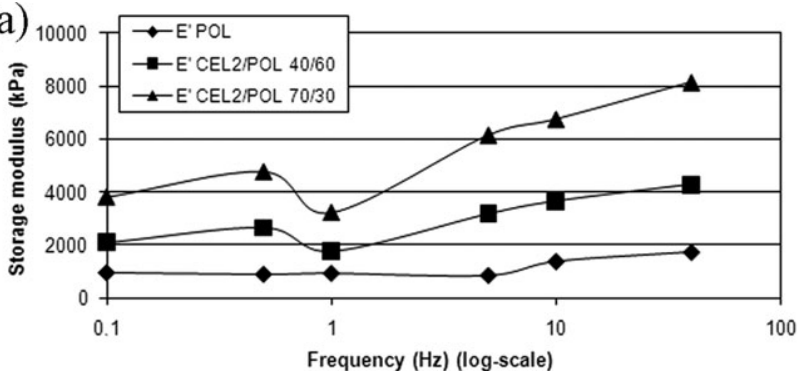

(b)

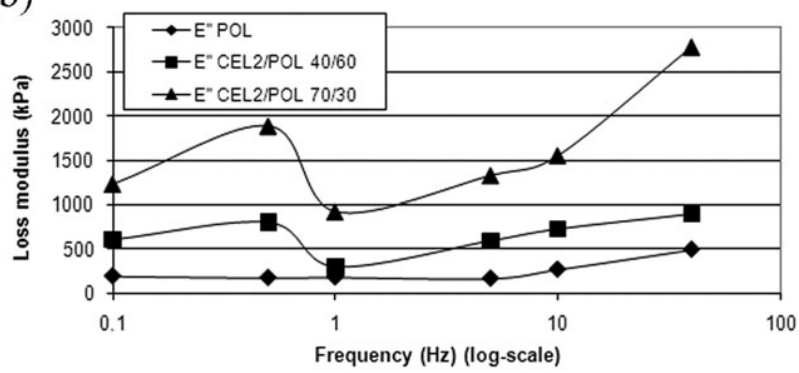

(c)

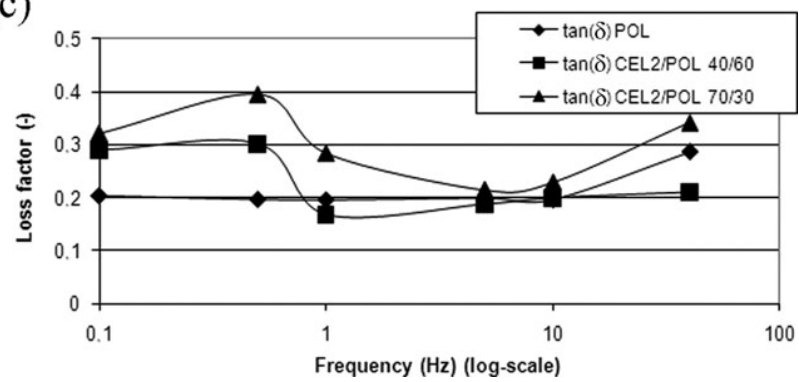

FIGURE 7. Dynamic mechanical analysis of CEL2/POL scaffolds showing: (a) the storage $\left(E^{\prime}\right)$, (b) loss $\left(E^{\prime}\right)$ modulus behavior, and (c) the loss factor ( $\tan \delta$ ) for increasing frequencies under dynamic compression solicitation.

$1 \mathrm{~Hz}$ as reference values for purpose of comparison (Table III). These values of storage modulus are comparable, as order of magnitude, to those of Young's modulus acquired under static conditions for all the three scaffold batches.

The loss factor $\tan \delta=E^{\prime \prime} / E^{\prime}$, measuring the ability of dissipating the cyclic mechanical energy in form of heat, is plotted in Figure 7(c). Composite scaffolds show a remarkable dissipation ability, related to damping properties, especially at low and high frequencies, which can be a very useful feature in view of in vivo implantation.

Investigation of the mechanical properties of glass/ polymer scaffolds by DMA is new with respect to previous literature. However, we cannot ignore that the results

TABLE III. Mean Values of Storage $\left(E^{\prime}\right)$ and Loss $\left(E^{\prime}\right)$ Modulus of the Different Scaffolds Series Acquired at a Frequency of $1 \mathrm{~Hz}$

\begin{tabular}{lcc}
\hline CEL2/POL sample & $E^{\prime}(\mathrm{kPa})$ & $E^{\prime \prime}(\mathrm{kPa})$ \\
\hline $0 / 100$ & 920 & 180 \\
$40 / 60$ & 1768 & 295 \\
$70 / 30$ & 3220 & 916 \\
\hline
\end{tabular}

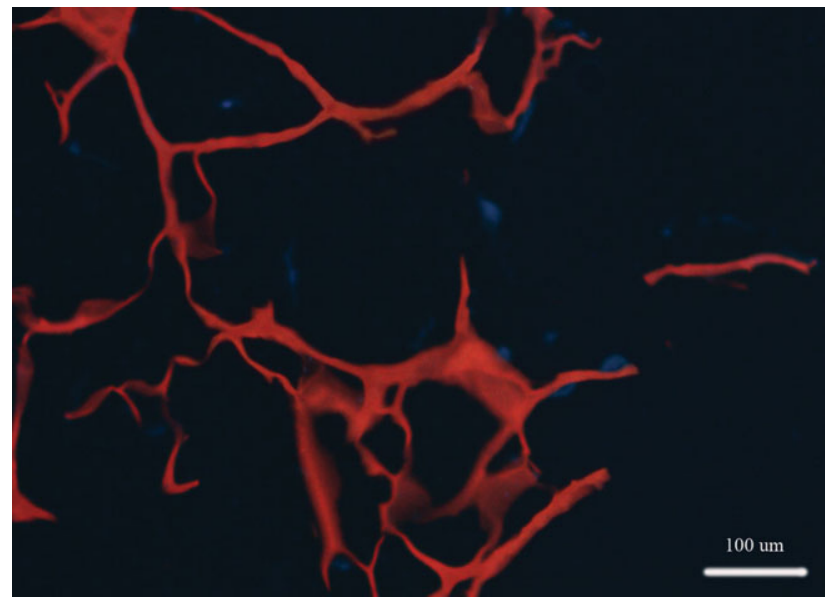

FIGURE 8. Section of the central part of CEL2/POL 30/70 scaffold that evidenced the presence of MG63 stained with DAPI (blue). [Color figure can be viewed in the online issue, which is available at wileyonlinelibrary.com.]

presented in this work represents a preliminary achievement, as the samples were tested in dry state; more accurate data could come from DMA on the composite scaffolds in wet state, to better mimic the physiological conditions in which the materials will be potentially used.

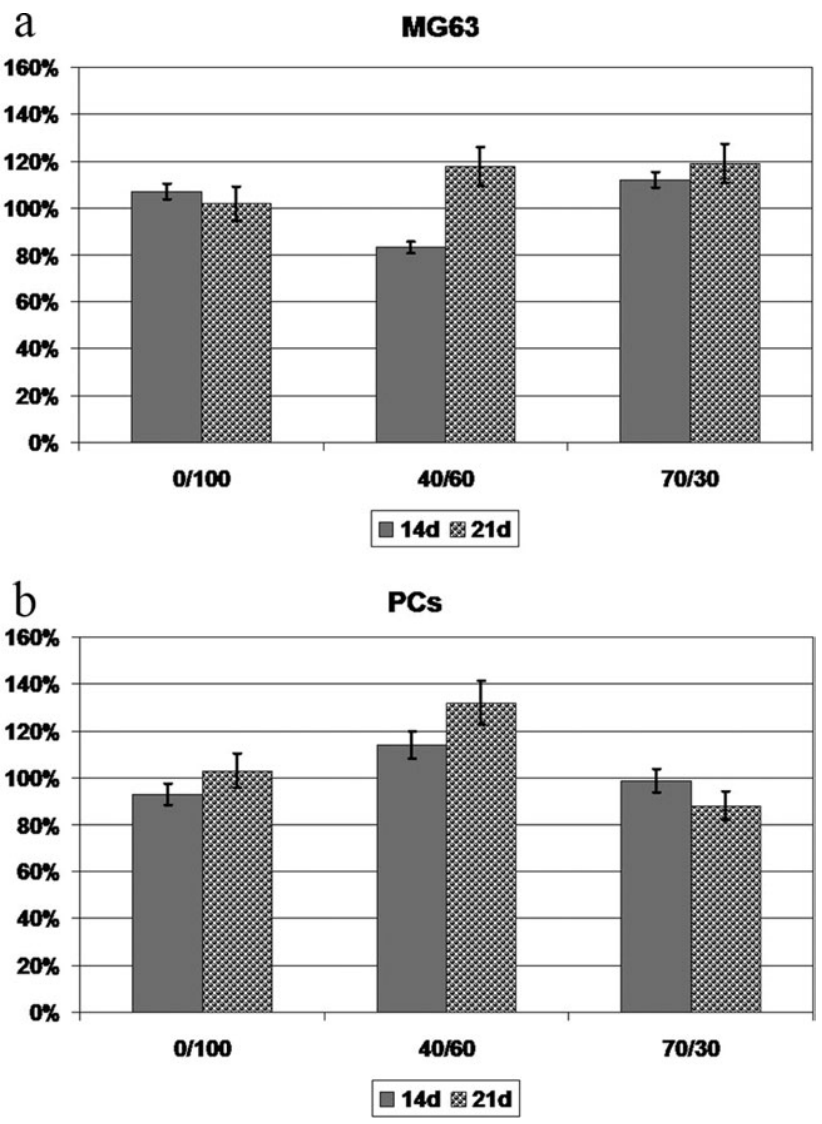

FIGURE 9. Histogram of MTT test performed on MG63 (a) and PCs (b) cultured on CEL2/POL 100/0, 40/60, and 30/70 for 14 and 21 days. 

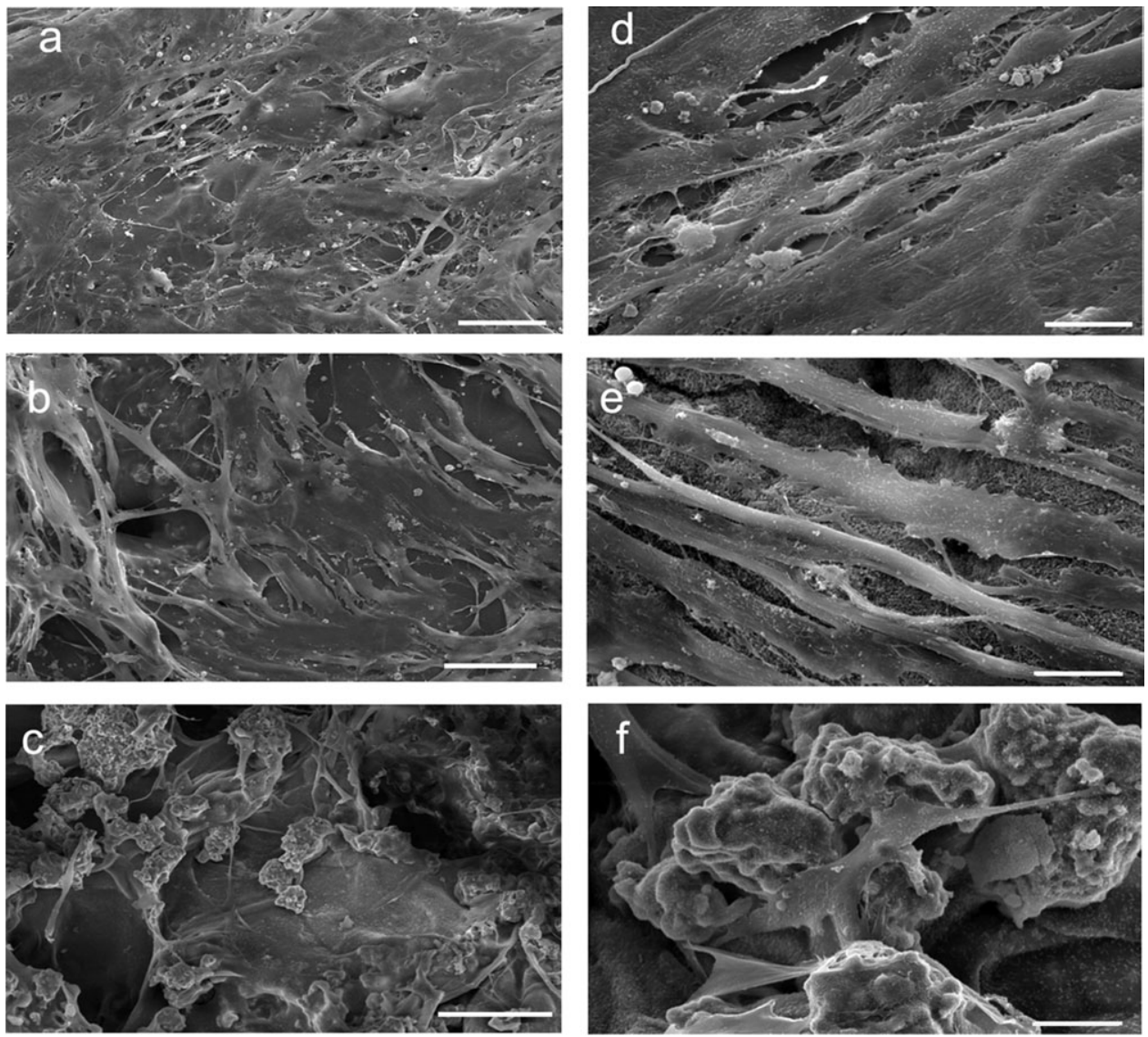

FIGURE 10. SEM observation of PCs cultured for 14 days on CEL2/POL 100/0 (a,d), CEL2/POL 40/60 (b,e), and CEL2/POL 30/70 (c,f). Scale bar a-c $100 \mu \mathrm{m}$; scale bar d-f $20 \mu \mathrm{m}$.

\section{Cell compatibility}

Overall, cells displayed a good ability to interact with the different tested scaffolds which did not modify cell metabolic activity at the analyzed points (i.e. 14 and 21 days). Histological sections stained with DAPI demonstrated the presence of a small amount of cells in the central part of the scaffold (Fig. 8).

Comparing the data obtained at 14 and 21 days of culture, MTT test proved only a slight difference between the two cytotypes analyzed (Fig. 9). On CEL2/POL 0/100, an increase in cell proliferation was observed only for PCs while no changes were detected for MG63. A significant $(p<0.01)$ increase in cell proliferation for both cell cytotypes cultured on CEL2/POL 40/60. Interestingly, while no differences were detected in MG63 cultured on CEL2/POL $70 / 30$ a significant $(p<0.01)$ reduction of this parameter was detected for PCs.

SEM observations of PCs cultured on the different scaffolds were consistent with MTT data, showing changes in cell morphology (Figs. 10 and 11). At 14 days of culture, cells on CEL2/POL 0/100 were elongated forming a uniform sheet on the scaffolds' surface [Fig. 10(a,d)]. At 21 days, cells resulted more spreaded and tried to grow inside pores [Fig. 11(a,d)]. On CEL2/POL 40/60 [Figs. 10(b) and 11(b)] cells were elongated and less uniformly distributed in comparison with CEL2/POL 0/100. This phenomenon may be at least in part related to not uniform surface of the scaffold that hampered initial cell adhesion and, consequently, cell proliferation. The reduced cell density was more evident on CEL2/POL 70/30, which were the scaffolds with the most uneven surface. On these scaffolds, cells displayed a more irregular morphology that stretched out to cross scaffold macroporosity [Fig. 10(c,f)]. This irregular star-shaped aspect was maintained also at 21 days of culture [Fig. 11(c,f)], suggesting that different chemical composition, affecting scaffold macro- and microstructure and stiffness, could influence cell differentiation, ${ }^{64,65}$ as already shown in our previous work. ${ }^{66}$ Cell proliferation decreases as differentiation signs increased. In this respect, our results suggest that scaffolds with an increased amount of inorganic phase (i.e. CEL2/POL 70/30) may stimulate PCs differentiation into an osteoblastic progeny. In contrast, MG-63 cells appear to hold different cross-talks with the different tested scaffolds than PCs. These cells are immortalized, immature and have a high proliferative potential that probably slow down their differentiation capability without any additional treatment.

\section{CONCLUSIONS}

Freeze-dried CEL2/POL scaffolds (0/100; 40/60; 70/30 wt $\% / w t)$ showed an interconnected network of macropores with $100-200 \mu \mathrm{m}$ average size as shown by SEM and $\mu$-CT analysis. As the amount of CEL2 increased, the total porosity 

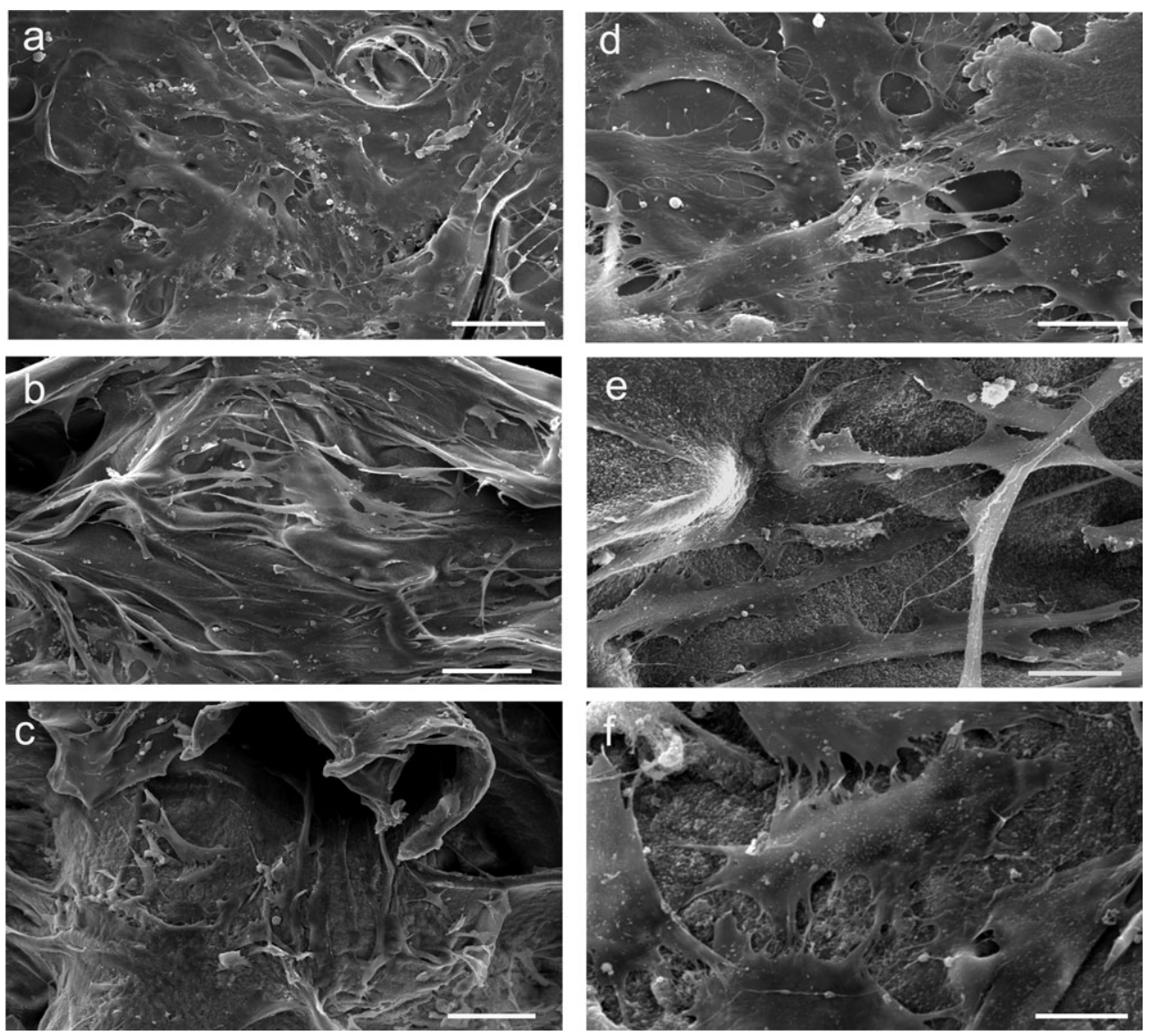

FIGURE 11. SEM observation of PCs cultured for 21 days on CEL2/POL 100/0 (a,d), CEL2/POL 40/60 (b,e), and CEL2/POL 30/70 (c,f). Scale bar a-c $100 \mu \mathrm{m}$; scale bar d-f $20 \mu \mathrm{m}$.

and the mean pore size slightly decreased because the bioactive glass particles deposited onto the polymeric pore walls and filled part of the void space of the matrix. Furthermore, composites containing CEL2 were particularly interesting due to their stability in aqueous solution as evidenced by swelling tests and to their pronounced bioactivity and expected consequent bone-bonding ability during in vivo trials. In fact, they are expected to react with physiological fluids, forming hydroxyapatite layers on the film surface containing inorganic phase and creating strong bonds to hard and soft tissues through cellular activity. As evidenced by SBF immersion tests, an increasing CEL2 amount greatly enhanced the bioactivity of the scaffold: glass particles behaved as nucleation sites for apatite crystallization. The elastic modulus of the composites with the highest glass content (70 wt \%) was found to be comparable to that of alveolar bone. DMA carried out on the composite scaffolds in dry state shows that the samples exhibit a remarkable dissipation ability especially at low and high frequencies; this damping effect could be a useful feature in view of in vivo implantation.

Additional work is in progress to increase the mechanical resistance of the scaffolds by the substitution of gelatin with collagen in the organic phase and the use of combined crosslinking techniques and/or blending strategies with the aim to extend the application of CEL2-based composites to the repair of other bone defects.
Morphological and biochemical analysis performed with a continuous cell line (MG63) and with human periostealderived stem cells seeded on the CEL2/POL scaffolds showed that cells maintain their metabolic activity and ability to proliferate on the scaffold. Differentiation and over proliferation occurred to PCs, at the increase of bioactive glass concentration, reveal the capacity of tested scaffold to modulate osteogenic properties.

Therefore, the proposed scaffolds, which are resorbable, bioactive, and capable to modulate cell proliferation/ differentiation processes, may be interesting tools in osteochondral tissue regeneration. Further studies are in progress to validate this hypothesis.

\section{REFERENCES}

1. Bauer TW, Muschler GF. Bone graft materials. An overview of the basic science. Clin Orthop 2000;371:10-27.

2. Chen JD, Wang YJ, Wei K, Zhang SH, Shi XT. Self-organization of hydroxyapatite nanorods through oriented attachment. Biomaterials 2007; 14:2275-2280.

3. Wang Y, Yang C, Chen X, Zhao N. Development and characterization of novel biomimetic composite scaffolds based on bioglasscollagen-hyaluronic acid-phosphatidylserine for tissue engineering applications. Macr Mater Eng 2006;291:254-262.

4. Rodrigues $C V$, Serricella $P$, Linhares $A B$, Guerdes RM, Borojevic $R$, Rossi MA, Duarte ME, Farina M. Characterization of a bovine collagen-hydroxyapatite composite scaffold for bone tissue engineering. Biomaterials 2003;24:4987-4997. 
5. Mann S. Molecular tectonics in biomineralization and biomimetic materials chemistry. Nature 1993;365:499-505.

6. Hench LL, Splinter RJ, Allen WC, Greenlee TK. Bonding mechanisms at the interface of ceramic prosthetic materials (5th Edn). J Biomed Mater Res Symp 1971;2:17-141.

7. Baino F, Vitale-Brovarone C. Three-dimensional glass-derived scaffolds for bone tissue engineering: current trends and forecasts for the future. J Biomed Mater Res A 2011;97:514-535.

8. Schepers EJ, Ducheyne PJ. Bioactive glass particles of narrow size range for the treatment of oral bone defects: a 1-24 month experiment with several materials and particle sizes and size ranges. Oral Rehabil 1997;24:171-181.

9. Mengel R, Schreiber D, Flores-de-Jacoby L. Bioabsorbable membrane and bioactive glass in the treatment of intrabony defects in patients with generalized aggressive periodontitis: results of a 5-year clinical and radiological study. J Periodontol 2006;77:1781-1787.

10. Maquet V, Blacher S, Pirard R, J-.P. Pirard R, Vyakarnam MN, Jérôme R. Preparation of macroporous biodegradable poly(L-lactide-co- $\varepsilon$-caprolactone) foams and characterization by mercury intrusion porosimetry, image analysis and impedance spectroscopy. J Biomed Mater Res 2003;66A:199-213.

11. Boccaccini AR, Maquet V. Bioresorbable and bioactive polymer/ bioglass composites with tailored pore structure for tissue engineering applications. Compos Sci Technol 2003;63:2417-2429.

12. Leach JK, Kaigler D, Wang Z, Krebsbach PH, Mooney DJ. Coating of VEGF-releasing scaffolds with bioactive glass for angiogenesis and bone regeneration. Biomaterials 2007;27:3249-3255.

13. Bergeron E, Marquis ME, Chrétien I, Faucheux N. Differentiation of preosteoblasts using a delivery system with BMPs and bioactive glass microspheres. J Mater Sci Mater Med 2007;18:255-263.

14. Bosetti M., Cannas M. The effect of bioactive glasses on bone marrow stromal cells differentiation. Biomaterials 2005;26: 3873-3879.

15. Hattar S, Loty S, Gaisser D, Berdal A, Sautier JM. Effects of 58 S sol-gel glasses on the temporal expression of bone markers during mouse osteoblastic differentiation. J Biomed Mater Res A 2006:6:811-819.

16. Sarasam AR, Samli Al, Hess L, Ihnat MA, Madihally SV. Blending chitosan with polycaprolactone: porous scaffolds and toxicity. Macromol Biosci 2007;7:1160-1167.

17. Pangburn SH, Trescony PV, Heller J. Lysozyme degradation of partially deacetylated chitin, its films and hydrogels. Biomaterials 1982;3:105-108.

18. Davies RC, Neuberger A, Wilson B. The dependence of lysozyme activity on $\mathrm{pH}$ and ionic strength. Biochem Biophys Acta 1969; 178:294-305.

19. Nordtveit RJ, Varum KM, Smidsrod O. Degradation of partially Nacetylated chitosans with hen egg white and human lysozyme. Carb Polym 1996;29:163-167.

20. Kolodziejska I, Piotrowska B. The water vapour permeability, mechanical properties and solubility of fish gelatin-chitosan films modified with transglutaminase or 1-ethyl-3-(3-dimethylaminopropyl) carbodiimide (EDC) and plasticized with glycerol. Food Chem 2007;103:295-300.

21. Mao J, Zhao L, Yin YJ, Yao K. Structure and properties of bilayer chitosan-gelatin scaffolds. Biomaterials 2003;24:1067-1074.

22. Chen T, Embree HD, Brown EM, Taylor MM, Payne GF. Enzymecatalyzed gel formation of gelatin and chitosan: potential for in situ applications. Biomaterials 2003;24:2831-2841.

23. Mao J, Zhao L, de Yao K, Shang Q, Yang G, Cao Y. (2003) Study of novel chitosan-gelatin artificial skin in vitro. J Biomed Mater Res A 64:301-308.

24. Xia W, Liu W, Cui L, Liu Y, Zhong W, Liu D, Wu J, Chua K, Cao Y. Tissue engineering of cartilage with the use of chitosan-gelatin complex scaffolds. J Biomed Mater Res B 2004;71:373-380.

25. Burg KJL, Porter S, Kellam JF. Biomaterial developments for bone tissue engineering. Biomaterials 2000;21:2347-2359.

26. Barry FP, Murphy JM. Mesenchymal stem cells: clinical applications and biological characterization. Int J Biochem Cell Biol 2004 36:568-584.

27. Arnsdorf EJ, Jones LM, Carter DR, Jacobs CR. The periosteum as a cellular source for functional tissue engineering. Tissue Eng Part A 2009;15:2637-2642.
28. Stich S, Loch A, Leinhase I, Neumann K, Kaps C, Sittinger M, Ringe J. Human periosteum-derived progenitor cells express distinct chemokine receptors and migrate upon stimulation with CCL2, CCL25, CXCL8, CXCL12, and CXCL13. Eur J Cell Biol 2008: 87:365-376.

29. Duarte ML, Ferreira MC, Marvao MR, Rocha J. Determination of the degree of acetylation of chitin materials by $13 \mathrm{C} \mathrm{CP/MAS} \mathrm{NMR}$ spectroscopy. I J Biol Macromol 2001;28:359-363.

30. Vitale-Brovarone C, Verné E, Robiglio L, Appendino P, Bassi F, Martinasso G, Muzio G, Canuto R. Development of glass-ceramic scaffolds for bone tissue engineering: characterization, proliferation of human osteoblasts and nodule formation. Acta Biomater 2007;3:199-208.

31. Tarleton ES, Robinson JP, Smith SJ, Na JJW. New experimental measurements of solvent induced swelling in nanofiltration membranes. J Membr Sci 2005;261:129-135.

32. Kokubo T, Takadama $\mathrm{H}$. How useful is SBF in predicting in vivo bone bioactivity? Biomaterials 2006;27:2907-2915.

33. Wang H, Li Y, Zuo Y, Li J, Ma S, Cheng L. Biocompatibility and osteogenesis of biomimetic nanohydroxyapatite/polyamide composite scaffolds for bone tissue engineering. Biomaterials 2007; 28:3338-3348.

34. Barker MK, Seedhom BB. Articular cartilage deformation under physiological cycling loading - apparatus and measurement technique. J Biomech 1997;30:377-381.

35. Garner E, Lakes R, Lee T, Swan C, Brand R. Viscoelastic dissipation in compact bone: implications for stress-induced fluid flow in bone. J Biomech Eng 2000;122:166-172.

36. Ghosh S, Gutierrez V, Fernandez C, Rodriguez-Perez MA, Viana JC, Reis RL, Mano JF. Dynamic mechanical behavior of starchbased scaffolds in dry and physiologically simulated conditions: Effect of porosity and pore size. Acta Biomater 2008;4:950-959.

37. Dominici M, Le Blanc K, Mueller I, Slaper-Cortenbach I, Marini F, Krause D, Deans R, Keating A, Prockop DJ, Horwitz E. Minimal criteria for defining multipotent mesenchymal stromal cells. The International Society for Cellular Therapy position statement. Cytotherapy 2006:8:315-317.

38. Leon y Leon CA. New perspectives in mercury porosimetry. Adv Colloid Interface Sci 1998;76-77:341-372.

39. Kuboki $Y$, Takita H, Kobayashi D, Tsuruga E, Inoue M, Murata M, Nagai N, Dohi $Y$, Ohgushi H. BMP-induced osteogenesis on the surface of hydroxyapatite with geometrically feasible and nonfeasible structures: topology of osteogenesis. J Biomed Mater Res 1998:9:190-199.

40. Story BJ, Wagner WR, Gaisser DM, Cook SD, Rust-Dawicki AM. In vivo performance of a modified CSTi dental implant coating. Int J Oral Maxillofac Implants 1998;13:749-757.

41. Zeltinger J, Sherwood JK, Graham DA, Müeller R, Griffith LG. Effect of pore size and void fraction on cellular adhesion, proliferation, and matrix deposition. Tissue Eng 2001;7:557-572.

42. Ranucci C, Moghe PV. Polymer substrate topography actively regulates the multicellular organization and liver-specific functions of cultured hepatocytes. Tissue Eng 1999;5:407-420.

43. Haugh MG, Murphy CM, O’Brien FJ. Novel freeze-drying methods to produce a range of collagen-glycosaminoglycan scaffolds with tailored mean pore sizes. Tissue Eng Part C Methods 2010;16: 887-894.

44. Wu X, Liu $Y$, Li X, Wen $P$, Zhang $Y$, Long $Y$, Wang $X$, Guo $Y$, Xing $F$, Gao J. Preparation of aligned porous gelatin scaffolds by unidirectional freeze-drying method. Acta Biomater 2010;6: 1167-1177.

45. Janaki K, Elamathi S, Sangeetha D. Development and characterization of polymer ceramic composites for orthopedic applications. Trends Biomater Artif Organs 2008;22:169-178.

46. Hench LL. Bioceramics. J Am Ceram Soc 1998;81:1705-1728.

47. Hench LL. Bioactive materials: the potential for tissue regeneration. J Biomed Mater Res 1998;41:511-518.

48. Kitsugi T, Yamamuro T, Nakamura T, Kokubo T. Bone bonding behavior of $\mathrm{MgO}-\mathrm{CaO}-\mathrm{SiO}_{2}-\mathrm{P}_{2} \mathrm{O}_{5}-\mathrm{CaF}_{2}$ glass (mother glass of A.W-glass-ceramics. J Biomed Mater Res 1989;23:631-648.

49. Cai $X$, Tong $H$, Shen $X$, Chen W, Yan J, Hu J. Preparation and characterization of homogeneous chitosan-polylactic acid/hydroxyapatite nanocomposite for bone tissue engineering and 
evaluation of its mechanical properties. Acta Biomater 2009;5: 2693-2703.

50. Kong LJ, Gao Y, Cao WL, Gong YD, Zhao NM, Zhang XF. A study on the bioactivity of chitosan/nano-hydroxyapatite composite scaffolds for bone tissue engineering. Eur Polym J 2006;42: 3171-3179.

51. Le Geros RZ Calcium phosphates in oral biology and medicine. In: Myers Karger $\mathrm{H}$, editor. Monographs in Oral Science. Basel: AG Publishers; 1991. p 82-107.

52. Miyaji F, Kim HM, Handa S, Kokubo T, Nakamura T. Bonelike apatite coating on organic polymers: novel nucleation process using sodium silicate solution. Biomaterials 199;20:913-919.

53. Oliveira AL, Malafaya PB, Reis RL. Sodium silicate gel as a percursor for the in vitro nucleation and grow of a bone-like apatite coating in compact and porous polymeric structures. Biomaterials 2003;24:2575-2584.

54. Gentile $\mathrm{P}$, Chiono V, Boccafoschi $\mathrm{F}$, Baino F, Vitale-Brovarone $\mathrm{C}$ Vernè $E$, Barbani N, Ciardelli G. Composite films of gelatin and hydroxyapatite/bioactive glass for tissue-engineering applications. J Biomater Sci Polym Ed 2010;21:1207-1226.

55. Vitale-Brovarone $C$, Baino $F$, Vernè E. High strength bioactive glass-ceramic scaffolds for bone regeneration. J Mater Sci: Mater Med 2009;20:643-653.

56. Ma PX, Choi JW. Biodegradable polymer scaffolds with welldefined interconnected spherical pore network. Tissue Eng 2001; 7:23-33.

57. Kanungo BP, Silva E, Van Vliet K, Gibson LJ. Characterization of mineralized collagen-glycosaminoglycan scaffolds for bone regeneration. Acta Biomater 2008:4:490-503.

58. Armitage GC. Periodontal diagnoses and classification of periodontal diseases. Periodontology 2004;34:9-21.
59. Oliveira JM, Rodrigues MT, Silva SS, Malafaya PB, Gomes ME, Viegas CA, Dias IR, Azevedo JT, Mano JF, Reis RL. Novel hydroxyapatite/chitosan bilayered scaffold for osteochondral tissue-engineering applications: scaffold design and its performance when seeded with goat bone marrow stromal cells. Biomaterials 2006;27:6123-6137.

60. Ohyabua Y, Adegawa T, Yoshioka T, Ikoma T, Uemura T, Tanaka $J$. A collagen sponge incorporating a hydroxyapatite/chondroitinsulfate composite as a scaffold for cartilage tissue engineering. $J$ Biomater Sci Polym Ed 2009;20:1861-1874.

61. Tampieri A, Sandri M, Landi E, Pressato D, Francioli S, Quarto R, Martin I. Design of graded biomimetic osteochondral composite scaffolds. Biomaterials 2008;29:3539-3546.

62. Garner E, Lakes R, Lee T, Swan C, Brand R. Viscoelastic dissipation in compact bone: implications for stress-induced fluid flow in bone. J Biomech Eng 2000;122:166-72.

63. Malafaya PB, Santos TC, Van Griensven M, Reis RL. Morphology, mechanical characterization and in vivo neovascularisation of chitosan particle aggregated scaffold architectures. Biomaterials 2008;29:2914-3926.

64. Mattioli-Belmonte M., Vozzi G, Kyriakidou K, Pulieri E, Lucarini G, Vinci B, Pugnaloni A, Biagini G, Ahluwalia A. Rapid-prototyped and salt-leached PLGA scaffolds condition cell morpho-functional behavior. J Biomed Mater Res A 2008;85:466-476.

65. Ciardelli G, Gentile P, Chiono V, Mattioli-Belmonte M, Vozzi G, Barbani N, Giusti P. Enzymatically crosslinked porous composite matrices for bone tissue regeneration. J Biomed Mater Res A 2010;92:137-151.

66. Gigante A, Manzotti S, Bevilacqua C, Orciani M, Di Primio R, Mattioli-Belmonte M. Adult mesenchymal stem cells for bone and cartilage engineering: effect of scaffold materials. Eur J Histochem 2008;52:169-174. 